\title{
As medidas de austeridade fiscal implementadas nos PIGS: por que a Europa pode entrar novamente em recessão?
}

\author{
Luciano Luiz Manarin D’Agostini*
}

\begin{abstract}
RESUMO - A União Europeia (UE) e o Fundo Monetário Internacional (FMI) anunciaram tardiamente, no mês de maio, um pacote de ajuda no valor de 750 bilhões de euros na tentativa de: (i) evitar um efeito contágio sobre outros países que fazem parte da Zona do Euro decorrente dos problemas fiscais na Grécia; (ii) proteger o euro contra futuras depreciações excessivas, (iii) desfragmentar a Zona do Euro. Pacotes de austeridade fiscal nos países foram recentemente anunciados em função do auxílio do BCE e FMI. Nesses sentidos o artigo mostra: (i) quais foram as principais medidas fiscais tomadas pelos PIGS e (ii) quais medidas monetárias poderão ser implantadas nos próximos períodos. O resultado técnico provável será, no curto prazo, o baixo crescimento dos PIB's dessas economias, em função basicamente dos menores níveis de salários para o trabalhador, maior carga de impostos e, consequentemente, menor consumo. Como os países da Zona do Euro ainda têm um longo caminho de austeridade fiscal pela frente, aumentam as probabilidades de uma nova recessão na região e problemas de crescimento no médio e longo prazo.
\end{abstract}

Palavras-chave: Política fiscal. Zona do Euro. Recessão.

\section{INTRODUÇÃO}

O pacote emergencial de 750 bilhões de euros, anunciado no mês de maio do corrente ano não impedirá que a mais ambiciosa construção monetária institucional da nossa época, a Zona do Euro, venha a ser submetida a duros testes nos próximos períodos. Os critérios macroeconômicos estabelecidos pelo Tratado de Maastricht e pelo Pacto de Estabilidade e Crescimento foram, na prática, superados pelos problemas de coordenação fiscal e monetária observados nos últimos anos. Questiona-se as relações existentes entre as condutas da política monetária de um banco central único da Zona do Euro, o Banco Central Europeu (BCE) e as políticas fiscais conduzidas pelos países que fazem parte da Zona do Euro.

Existe, na prática, uma falha estrutural entre as coordenações da política monetária do BCE e as coordenações fiscais em cada um dos países. Um país soberano em sua moeda e

\footnotetext{
* Economista e consultor financeiro. Doutor em Desenvolvimento Econômico da Universidade Federal do Paraná. Professor dos Programas de Pós-Graduação em Finanças pela UNINTER/IBPEX. Endereço eletrônico: lucianodagostini@hotmail.com.
} 
títulos públicos pode, a qualquer momento, financiar a dívida emitindo moeda ou vendendo títulos públicos no mercado aberto pagando um yield ou uma remuneração sobre o valor de face. Normalmente as remunerações dos títulos públicos são dadas por uma taxa de desconto dados, por exemplo, pelas taxas de juros, índices de preços, índices cambiais, pré ou pósfixados.

Logicamente essas formas monetárias de financiamento que os governos têm são válidas se o risco desses produtos financeiros, moeda e títulos públicos, são amplamente aceitos pelo mercado. Ou seja, o risco de deter moeda desse país basicamente é a inflação. Inflação alta deprecia a moeda local. O risco de deter títulos públicos basicamente refere-se à capacidade de pagamento no prazo determinado pelos governos para honrar esses compromissos. Os dois, moeda e títulos públicos, além do risco, devem ter liquidez. Ou seja, a moeda deve ser amplamente aceita para transações nacionais e inclusive seria interessante ter algum tipo de liquidez internacional. Nesse sentido a moeda euro, atualmente, satisfaz essas condições.

Agora os títulos públicos, além de serem instrumentos de política monetária, são formas poderosas de financiamento de curto, médio e longo prazo dos governos centrais. Então, a avaliação das condições macroeconômicas para compra desses tipos de papeis para incorporar numa cesta de produtos financeiros devem ser monitorados constantemente. Em especial, o governo gasta e também arrecada. Na média, ao longo do tempo, as taxas de crescimento das receitas do governo devem ser maiores que as taxas de crescimento das despesas do governo. Ou seja, o controle fiscal deve ser permanentemente monitorado para que a dinâmica macroeconômica não seja "caótica negativa".

O estado caótico negativo começou com a crise de liquidez e confiança interbancária mundial, iniciada pelos problemas de inadimplência no mercado imobiliário americano ainda na década passada e que se agravou em setembro de 2008, com a falência do Lehman Brothers. Em 2009, em resposta à crise de liquidez mundial, os países da Zona do Euro, através do Banco Central Europeu, reduziram os juros, similar as demais economias dos países desenvolvidos e emergentes. A política monetária européia foi, em grande medida, coordenada com condutas de políticas monetárias de outros bancos centrais, espalhados pelo mundo.

Acontece que a política fiscal entre os países da Zona do Euro foi descoordenada entre eles e descoordenada entre as ações de política monetária do BCE. É fato que, no geral, políticas fiscais expansionistas foram praticadas nos países que sofreram com a crise de 2008. 
Recorreram ao receituário tradicional do déficit público, tendo em vista, antes de mais nada, proteger a liquidez do sistema financeiro que estava caótico.

Individualmente, portanto, os países da Zona do Euro são desprovidos de políticas monetárias e cambiais próprias, ou seja, são totalmente dependentes das ações do BCE. Guiados pelas agências de classificação de risco e que concedem notas de créditos a ativos financeiros do governo e de empresas, os países da Zona do Euro tornaram-se alvos da armadilha especulativa global. É fácil entender a armadilha a partir de instrumentos monetários. Como foco primordial do estopim da crise da Zona do Euro em 2010 temos a Grécia. Sua irresponsabilidade fiscal tornou explícita e dramática a descoordenação entre a parte monetária e a parte fiscal. O governo grego não pode imprimir moeda porque quem imprime moeda é o BCE. O governo grego não pode mexer nem movimentar as taxas de juros porque quem altera as taxas de juros é o BCE. A Grécia também não pode alterar os demais instrumentos de controle monetário, como redescontos bancários e depósitos compulsórios. Sempre o mentor das movimentações dos instrumentos monetários é o BCE.

Para o governo grego, então, restam os títulos públicos. Os governos centrais podem emitir seus títulos e, no geral, obter financiamento no mercado financeiro a custos mais saudáveis para a economia nacional até o momento em que as agências de classificação de risco, que comandam a "manada" de investidores, concedem uma boa nota de crédito. Assim foi com a Grécia. Não podia financiar-se com moeda e controlar sua economia com juros próprios, mas podia financiar-se com títulos públicos soberanos. Mesmo sabendo dos problemas macroeconômicos enfrentados pela Europa, em especial fiscal, notas de crédito boas continuavam mantidas pelas principais agências de classificação de risco.

Quando o processo começa a se deteriorar, logicamente, as notas de crédito das dívidas soberanas começam a cair, inclusive, podendo passar rapidamente de "grau de investimento" para "nível especulativo". Ou seja, muitas vezes, pode ocorrer uma queda rápida da nota de crédito em vez de uma queda lenta e gradual. Como os títulos públicos gregos foram rebaixados a "grau especulativo", de um dia para o outro, sem gradualidade ao longo do tempo, o governo hoje consegue, em volume financeiro, vender bem menos quantidades de títulos soberanos do que quando estava com a nota de crédito boa. Isso significa que, se o financiamento via títulos públicos estava escasso quando a nota de crédito era boa vis-à-vis com seus gastos públicos elevadíssimos, agora, com o rebaixamento da nota e aumento de risco, o instrumento "venda de títulos públicos" no mercado aberto para financiar as dívidas gregas ficaram ainda mais minguados. É como se a pergunta ao investidor 
em renda fixa fosse: você aplica seu dinheiro em títulos do governo de Zimbabwe? Você aplica seu dinheiro em títulos do governo do Haiti? Você aplica seu dinheiro em títulos do governo da Grécia? Você aplica seu dinheiro em títulos do governo dos Estados Unidos? Pela comparação de critérios técnicos entre as dívidas dos países, mesmo com dúvidas e incertezas a respeito da economia americana, o investidor responderia: Estados Unidos, lógico! Mas o BCE optou inicialmente pela compra de títulos gregos.

Pois bem, em teoria, um país soberano pode fazer política monetária e política fiscal como bem entender. Via política monetária, portanto, a Grécia perde seu poder de Estado soberano e não tem mais controle da moeda, do câmbio e de liquidez da sua economia. E para completar seus títulos públicos não conseguem captar o volume de recursos requeridos. E se captam dinheiro com o instrumento título soberano, o dinheiro que financia o país é especulativo, de curto prazo, frágil em seus pilares. Como a nota de crédito dos títulos soberanos gregos permanecerá um bom tempo com a nota especulativa, o caso contrário, é mais difícil de ocorrer: notas positivas de crédito sendo concedidas de maneira rápida. Será sim, lenta e gradual. Ou seja, os títulos gregos terão de esperar muito até retornar as notas de créditos boas. Nesse sentido o BCE comprou o crédito.

O início da crise fiscal grega mostra realmente ao mundo que países que compõem a Zona do Euro, principalmente aqueles que têm pequena contribuição no PIB da região detêm restrições de política monetária, ou seja, politicamente, dentro do Banco Central Europeu, são incapazes de conduzir taxas de juros, depósitos compulsórios, redescontos bancários e demais instrumentos de controle monetário a seu favor. Alemanha e França, dentro do arcabouço do Banco Central Europeu, parecem que tem cadeiras majoritárias no processo de decisão monetária.

Restam, portanto, dado a incompatibilidade da política monetária e fiscal, se ajoelhar para o Fundo Monetário Internacional e para países que dominam as condutas de política monetária do Banco Central Europeu, ou seja, Alemanha e França, as duas maiores economias da região.

Aos países mais frágeis restou o amargo remédio que os economistas brasileiros da década de 80 conhecem muito bem: corte de gastos do governo e elevação de impostos. Nesse sentido, na Zona do Euro, que medidas de corte de gastos do governo foram tomadas? E que medidas de elevação de impostos foram tomadas? 


\section{PRINCIPAIS MEDIDAS DE AUSTERIDADE FISCAL NOS PIGS}

A Grécia aprovou o projeto de lei da reforma das pensões, depois de concordar com a UE e o FMI, um novo conjunto de medidas de austeridade que visam tirar o país da grave crise da dívida, a qual abala a Zona do Euro. Sob o acordo com a UE e o FMI, a Grécia planeja (planejar não é realmente concretizar o plano) reduzir seu déficit orçamentário de 13,6\% do PIB em 2009 para 8,1\% em 2010, 7,6 \% em 2011 até chegar aos 2,6 \% do PIB em 2014. As medidas de austeridade fiscal incluem o congelamento de salários do funcionalismo público até 2014. Natal, Páscoa e subsídios de férias de verão, também conhecidos aqui no Brasil como $13^{\circ}$ e $14^{\circ}$ salários, serão retirados dos funcionários públicos gregos que ganham acima de $€ 3.000,00$ por mês e está limitado a $€ 1.000$, para aqueles que ganham menos. Subsídios do setor público serão cortados em mais $8 \%$. Esses subsídios, que representam uma parte significativa da renda dos funcionários públicos em geral, foram cortados em 12 por cento em uma rodada de medidas de austeridade anunciadas em março. Isso significa que é a austeridade da austeridade fiscal. A taxa de imposto sobre o valor adicionado (IVA) foi aumentada em $2 \%$, de $21 \%$ para $23 \%$. O detalhe é que em março, o IVA havia sido elevado. Portanto, houve mais um ajuste para cima em pouco menos de 2 meses. Os impostos sobre o consumo de combustível, cigarros e álcool foram aumentados em mais 10\%. Com essas medidas o governo grego espera gerar receitas adicionais através de um imposto único para as empresas altamente rentáveis. Por fim, o governo anunciou que irá congelar as pensões em 2010, 2011 e 2012.

Na Irlanda o orçamento do governo para 2010, apresentado em dezembro de 2009, representa um déficit de $11,6 \%$ do PIB. Por enquanto, até meados de maio, a reforma fiscal irlandesa até agora são três orçamentos de austeridade apresentados em pouco mais de dois anos, em outubro de 2008, abril de 2009 e dezembro de 2010. Os dois primeiros orçamentos são focados em aumento de impostos. O orçamento de dezembro de 2010 refere-se a cortes de gastos de $€ 4$ bilhões, incluindo um corte nos salários do setor público. O congelamento da poupança, no valor de $€ 3$ trilhões estão previstas para cada 2011 e 2012.

Em Portugal, o governo aprovou medidas para reduzir o déficit orçamentário. Inclui queda de salários para funcionários do setor público e políticos de carreira, na ordem de $5 \%$. Também, aumentou o IVA, imposto sobre as vendas, rendas e lucros que variam de 1 a 2,5\%. Portugal planeja (planejar não é realmente concretizar o plano) reduzir seu déficit orçamentário de 9,4\% do PIB em 2009 para 7,3\% em 2010, 4,6 \% em 2011 até chegar aos 2\% do PIB em 2014. 
$\mathrm{Na}$ Espanha, o governo anunciou em maio, cortes de gastos no montante de $€ 15$ bilhões entre 2010 e 2011. Os salários dos servidores civis serão reduzidos em 5\% em 2010 e congelados em 2011. Outro corte virá dos investimentos públicos espanhois. Nesse sentido o governo espanhol revelou que pretende cortar $€ 6$ bilhões. Os cortes são destinados a acelerar a consolidação orçamentária e atingir os objetivos de queda do déficit público em relação ao PIB dos atuais 11,2\% em 2009, para 9,3\% em 2010, 6\% em 2011 até chegar a 3\% em 2014. E ainda, de acordo com o projeto de lei de pensões, previsto para ser votado pelo Parlamento Europeu em Junho, a idade legal de reforma para as mulheres será aumentada em cinco anos, para 65, com o objetivo de coincidir com a idade de aposentadoria para os homens e a para arrecadar mais.

\section{PRIMEIRAS CONCLUSÕES SOBRE AS PRINCIPAIS MEDIDAS DE AUSTERIDADE FISCAL NOS PIGS}

Basicamente as medidas de austeridade fiscal na Grécia, Portugal, Espanha e Irlanda resumem-se a corte de salários e gastos do governo combinado com aumento de impostos. Nas últimas décadas, quando países periféricos estavam em crise externa, o FMI desenhava as políticas fiscais e fazia o país endividado implementar. Isso no geral deprimia a demanda interna, pela queda do consumo (corte ou congelamento de salários e aumento dos impostos) e gastos do governo, gerando assim, excedentes de produção que não eram vendidos no mercado interno, mas que poderiam ser vendidos no mercado externo, via exportação. Com o excedente de produtos exportáveis juntamente com políticas cambiais destinadas a aumentar a competitividade internacional, o mecanismo poderia fazer o país com forte endividamento e incapacidade de pagamento no mercado financeiro sair do círculo vicioso, honrar suas dívidas via transmissão do balanço de pagamentos. Os custos sociais eram enormes, mas, do ponto de vista econômico, havia chances de obter algum resultado, dependendo do desempenho exportador e de seu efeito sobre a retomada do crescimento em algum momento futuro. Havia países em crise, mas o comércio internacional funcionava. Parece algo similar aos países europeus que estão com crise de dívidas, exceção que o cenário mundial agora é completamente diferente de 20 ou 30 anos atrás.

Em 2009, o comércio internacional diminuiu quase 10\% em quantidade e mais de $25 \%$ em valor. Com a estagnação batendo às portas dos EUA, do Japão e da própria Europa, a recessão que se impuser a qualquer um desses países não será resolvida pelas exportações, a menos que eles sejam grandes clientes da China e Índia, cujas economias não interromperam 
suas trajetórias de crescimento. Não é o caso da Grécia e dos países do sul da Europa, que estão diante de um retrocesso econômico sem, ainda, saída visível. Inclusive por suas condutas fiscais e renúncias em detrimento de uma única moeda na região, poderão inclusive, fazer com que a Europa da Região do Euro entre novamente em recessão.

Isso porque o BCE, ao decidir adquirir títulos dos governos europeus mais fragilizados como Grécia, Espanha, Portugal e Irlanda romperam a institucionalidade fiscalmonetária em vigor. Provavelmente, com a medida de compra de títulos públicos dos PIGS, o BCE diminuiu a capacidade de aumentar as taxas de juros nos próximos meses. Inclusive pode até continuar a diminuir. O BCE postergou a moratória de alguns países, protegeu credores e no curto prazo, deu fôlego e respiro a moeda euro. A parte importante não foi o pacote, mas a decisão monetária do Banco Central Europeu de comprar tais títulos. Isso permitiu que o mercado da dívida se acalmasse. Deu pequeno fôlego aos governos centrais.

Sem saída exportadora, similar aos países periféricos na década de 80, os países europeus alimentam uma nova recessão. Recessão que poderá chegar devido aos produtos chineses que ganham espaço no mercado mundial; problemas macroeconômicos nos EUA e Japão; a deflação devido à queda do consumo europeu; queda dos gastos governamentais em países europeus revelados nos últimos dias. A recessão e a queda na receita pública podem simplesmente se retroalimentar, um cenário caótico negativo, numa espiral de empobrecimento que provavelmente não evitará uma moratória futura, em piores condições.

Sem moeda própria, sem controle sobre o câmbio e com a capacidade de tributar entregue aos credores, a Grécia deixa de ser um Estado. Passa a ser um território governado por burocracias não eleitas, aquarteladas na União Européia e no FMI, cujas lealdades são outras. E se o processo semelhante atingir Portugal, Espanha, Irlanda e Itália, porque probabilidades existem, a Zona do Euro estará em perigo. $\mathrm{O}$ ambiente ainda mantém-se muito sensibilizado ao risco, uma vez que as medidas de ajuste fiscal e o pacote de ajuda ainda terão longos meses para serem implementados. Países da Zona Euro continuariam no centro das atenções, agregando cada vez mais volatilidade aos negócios e impondo quedas acentuadas nas principais bolsas mundiais, com contínua saída de capital estrangeiro em busca de títulos em caráter de classificação de agências de risco, com "grau de investimento". O "superpacote" da União Européia veio, na realidade, apenas para "bancar" a rolagem das dívidas e "segurar" o euro, minimizando a possibilidade dos riscos soberanos virarem financeiro, com a lembrança clara da crise de liquidez e crédito em 2008. 
A percepção que a redução dos enormes déficits fiscais e endividamento dos países da Zona do Euro só serão possíveis mediante medidas recessivas e impopulares (resta saber se a população européia irá aguentar) mantém o alerta de um segundo mergulho recessivo global. É praticamente inevitável a maior desaceleração da economia européia e um novo contágio na economia global. A Europa deve ter duplo mergulho na recessão e não haverá suporte fiscal para crescimento. Os juros não subirão tão cedo dado os problemas que começam a surgir devido à crise de 2008. Há riscos pequenos de desfragmentação da Zona do Euro. Inclusive as economias podem voltar a operar com uma moeda própria e soberana, apesar de pequena probabilidade de ocorrência. Mas, na economia global, onde de uma hora para outra surgem "buracos caóticos", tudo é possível. 